\title{
Maximally Flat IIR Fullband Differentiators with Flat Group Delay Responses
}

\author{
Slaviša Ilić, Ahmad Mohammed Salih, Majid Hamid Abdullah, and Dragiša Milić
}

\begin{abstract}
A new design method for maximally flat IIR fullband differentiators with flat group delay responses is derived in this paper. The design method starts from the flatness conditions of magnitude response and group delay response at the origin. After mathematical manipulations it shows that presented design method reduces to solving the system of linear equations. By increasing the orders of polynomials in numerator and denominator, degrees of flatness are increased, that is improvement in magnitude responses and group delay responses in terms of flatness is obtained.
\end{abstract}

Index Terms - fullband differentiators, maximally flat magnitude response, flat group delay response.

\section{INTRODUCTION}

Fullband differentiators are needed in various applications [1]-[7] where time-derivative of signal at input port need to be computed. Those filters, as any other type of filter functions, can be designed as finite impulse response filters (FIR) [8]-[15] and infinite impulse response filters (IIR) [16]-[23].

Frequency response of ideal fullband differentiators is as follows

$H_{d}\left(e^{j \omega}\right)=j \omega e^{-j \omega \tau_{0}}$,

where $\tau_{0}$ is desired group delay response. In this paper, the method derived in [24] is extended to design of maximally flat IIR fullband differentiators with flat group delay responses, whose transfer function can be expressed as [25], [16].

$H(z)=\left(1-z^{-1}\right) \frac{B(z)}{A(z)}=\frac{\tilde{B}(z)}{A(z)}$,

where

$A(z)=\sum_{i=0}^{N} a_{i} z^{-i}, B(z)=\sum_{i=0}^{N} b_{i} z^{-i}$,

$\tilde{B}(z)=\left(1-z^{-1}\right) B(z)=\sum_{i=0}^{M+1} \tilde{b}_{i} z^{-i}$,

Let's denote the phase response of $H(z)$ as $\theta(\omega)$. Obviously, $\theta(\omega)=\pi / 2$ if $B(z)$ does not have roots at $z=$ 1. Besides Introduction, the paper consists of three sections entitled Design Method, Design Examples and Conclusion.

Published on November 25, 2020.

Slaviša Ilić, Singidunum University, Serbia.

Ahmad Mohammed Salih, Higher Institute of Telecommunications, Iraq.

Majid Hamid Abdullah, Noontech Company, Iraq.

Dragiša Milić, Singidunum University, Serbia.

(e-mail: ddmilic@outlook.com)
In section Design Method, a new design method is derived such that maximally flat IIR fullband differentiators with flat group delay responses are obtained. Design examples are then presented.

\section{DESIGN METHOD}

From equation (1) it follows that maximally flat IIR fullband differentiators with flat group delay responses are characterized by flatness conditions

$$
\begin{aligned}
& \left.\left|H\left(e^{j \omega}\right)\right|\right|_{\omega=0}=0, \\
& \left.\frac{d\left|H\left(e^{j \omega}\right)\right|}{d \omega}\right|_{\omega=0}=1,
\end{aligned}
$$

$\left.\frac{d^{i}\left|H\left(e^{j \omega}\right)\right|}{d \omega^{i}}\right|_{\omega=0}=0, i=2,3, \ldots, K-1$,

$\left.\frac{d \theta(\omega)}{d \omega}\right|_{\omega=0}=-\tau_{0}$

$\left.\frac{d^{i} \theta(\omega)}{d \omega^{i}}\right|_{\omega=0}=0, i=2,3, \ldots, K-1$,

where $K$ is degree of flatness.

Applying Leibnitz's rule for higher derivatives [26] of $H\left(e^{j \omega}\right)=\left|H\left(e^{j \omega}\right)\right| e^{j \theta(\omega)}$ at $\omega=0$, and using previous equations, it shows that maximally flat IIR fullband differenztiators with flat group delay responses have frequency responses satisfying

$$
\begin{aligned}
& \left.\frac{d^{n}\left|H\left(e^{j \omega}\right)\right|}{d \omega^{n}}\right|_{\omega=0}=\left.\sum_{k=0}^{n}\left(\begin{array}{l}
n \\
k
\end{array}\right) \frac{d^{k}\left|H\left(e^{j \omega}\right)\right|}{d \omega^{k}} \frac{d^{n-k} e^{j \theta(\omega)}}{d \omega^{n-k}}\right|_{\omega=0}= \\
& \left.n \frac{d^{n-1} e^{j \theta(\omega)}}{d \omega^{n-1}}\right|_{\omega=0}=-j^{-n} n \tau_{0}^{n-1},
\end{aligned}
$$

As from equation (2)

$H\left(e^{j \omega}\right) A\left(e^{j \omega}\right)=\tilde{B}\left(e^{j \omega}\right)$

Differentiating $n$ times and applying Leibnitz's rule for higher derivatives [26] of left-hand side of previous equations, we get

$$
\begin{aligned}
& \frac{d^{n}}{d \omega^{n}}\left[H\left(e^{j \omega}\right) A\left(e^{j \omega}\right)\right]= \\
& \sum_{k=0}^{n}\left(\begin{array}{l}
n \\
k
\end{array}\right) \frac{d^{k} H\left(e^{j \omega}\right)}{d \omega^{k}} \frac{d^{n-k} A\left(e^{j \omega}\right)}{d \omega^{n-k}}=\frac{d^{n}}{d \omega^{n}} \tilde{B}\left(e^{j \omega}\right),
\end{aligned}
$$

and for $\omega=0$ after substituting (10) following is obtained 
$-\left.\sum_{k=0}^{n} j^{-k} k \tau_{0}^{k-1}\left(\begin{array}{l}n \\ k\end{array}\right) \frac{d^{n-k} A\left(e^{j \omega}\right)}{d \omega^{n-k}}\right|_{\omega=0}=\left.\frac{d^{n} \tilde{B}\left(e^{j \omega}\right)}{d \omega^{n}}\right|_{\omega=0}$.

Now, as from (3) and (4)

$\left.\frac{d^{n-k} A\left(e^{j \omega}\right)}{d \omega^{n-k}}\right|_{\omega=0}=(-j)^{n-k} \sum_{m=0}^{N} m^{n-k} a_{m}$

$\left.\frac{d^{n} \tilde{B}\left(e^{j \omega}\right)}{d \omega^{n}}\right|_{\omega=0}=(-j)^{n} \sum_{m=0}^{M+1} m^{n} \tilde{b}_{m}=-(-j)^{n} \sum_{m=0}^{M}((m+$

1) $\left.)^{n}-m^{n}\right) b_{m}$,

equation (13) can be rewritten as

$\sum_{m=0}^{N} \sum_{k=1}^{n} k\left(\begin{array}{l}n \\ k\end{array}\right) \tau_{0}{ }^{k-1} m^{n-k} a_{m}=\sum_{m=0}^{M}\left((m+1)^{n}-\right.$

$\left.m^{n}\right) b_{m}$.

Since it can be adopted that $a_{0}=1$, the number of unknown coefficients is $N+M+1$, and degree of flatness is also $K=N+M+1$. In other words, (16) is satisfied for $n=1,2, \ldots, K$. In matrix notation this reads

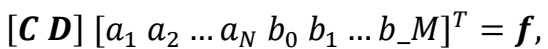

where $\boldsymbol{C}$ is $K \times N$ matrix, $\boldsymbol{D}$ is $K \times(M+1)$ matrix and $\boldsymbol{f}$ is $K \times 1$ vector:

$c_{n m}=\sum_{k=1}^{n} k\left(\begin{array}{l}n \\ k\end{array}\right) \tau_{0}{ }^{k-1} m^{n-k}, d_{n m}=(m-1)^{n}-$ $m^{n}, f_{n}=-n \tau_{0}^{n-1}$.

Unknown coefficients are:

$\left[\begin{array}{llllllll}a_{1} & a_{2} & \ldots & a_{N} & b_{0} & b_{1} & \ldots & b_{-} M\end{array}\right]^{T}=[\boldsymbol{C} \boldsymbol{D}]^{-1} \boldsymbol{f}$.

\section{DESIGN EXAMPLES}

Two examples are presented in this section. Example 1: $N=M=3, \tau_{0} \in\{2.4,2.5\}$. Ideal and obtained magnitude responses and obtained group delay responses are given in Fig. 1.
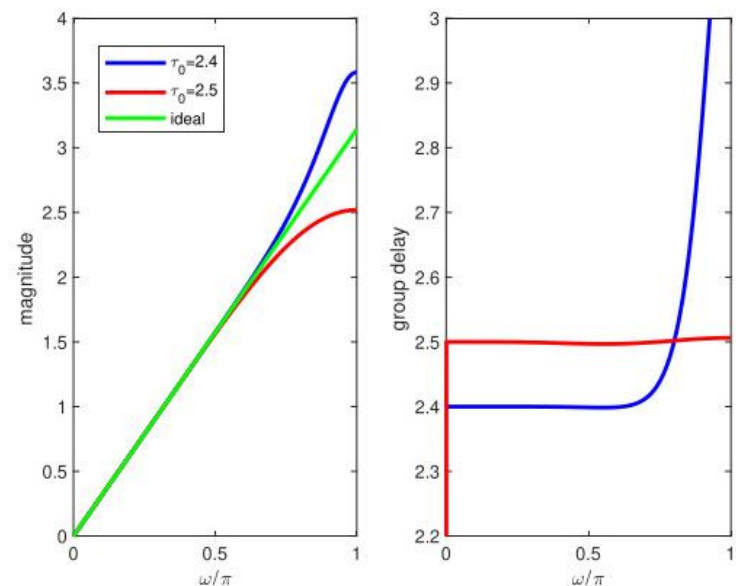

Fig. 1. Example 1. Obtained responses of proposed IIR fullband differentiators.

Example 2: $N=3, M=5, \tau_{0} \in\{2.25,2.5\}$. Ideal and obtained magnitude responses and obtained group delay responses are given in Fig. 2.
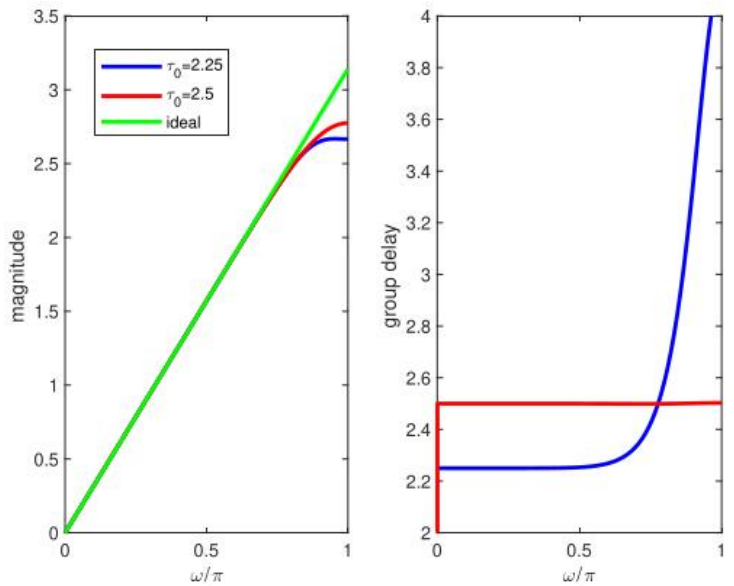

Fig. 2. Example 2. Obtained responses of proposed IIR fullband differentiators.

As can be concluded, proposed design method can be used to design IIR fullband differentiators. Determination of $\tau_{0}$ to obtain the best possible IIR fullband differentiator for some fixed value of $N$ and $M$ remains still an open problem.

\section{CONCLUSION}

A new IIR fullband differentiators design method is proposed in this paper. Resulting filters have maximally flat magnitude responses and flat group delay responses. By increasing the orders of polynomials in numerator and denominator, degrees of flatness are increased, ie. There will be improvement in magnitude responses and group delay responses in terms of flatness. Proposed IIR fullband differentiators design method reduces to solving a system of linear equations. Determination of $\tau_{0}$ to obtain the best possible solution for some $N$ and $M$ remains still an open issue.

\section{REFERENCES}

[1] G. F. Franklin, J. D. Powell, M. L. Workman et al., Digital control of dynamic systems. Addison-wesley Reading, MA, 1998, vol. 3.

[2] S. Usui and I. Amidror, "Digital low-pass differentiation for biological signal processing," IEEE Transactions on Biomedical Engineering, vol. BME-29, no. 10, pp. 686-693, 1982.

[3] V. Torre and T. A. Poggio, "On edge detection," IEEE Transactions on Pattern Analysis and Machine Intelligence, no. 2, pp. 147-163, 1986.

[4] M. I. Skolnik et al., Introduction to radar systems. McGraw-hill New York, 1980, vol. 3 .

[5] P. Laguna, N. V. Thakor, P. Caminal, and R. Jane, "Low-pass differentiators for biological signals with known spectra: application to ecg signal processing," IEEE transactions on biomedical engineering, vol. 37, no. 4, pp. 420-425, 1990 .

[6] A. E. Marble, C. M. Mc Intyre, R. Hastings-James, and C. W. Hor, "A comparison of digital algorithms used in computing the derivative of left ventricular pressure," IEEE Transactions on Biomedical Engineering, no. 7, pp. 524-529, 1981.

[7] V. D. Pavlovic and P. N. Lekic, "Determination of the Seismic Signal Differential Delay," in 5th Electronic Devices and Systems Conference EDS-98, Brno, Chezh Republic, 1998, pp. 5B.1-6.

[8] P. N. Lekic, A. Micic, P. C. Spalevic, J. B. Lekic, and I. D. Krstic, "Modified eigenfilter approach for designing digital full-band differentiator of arbitrary order," Revue Roumaine des Sciences Techniques Serie Electrotechnique et Energetique, 2014. 
[9] R. C. Kavanagh, "FIR differentiators for quantized signals," IEEE transactions on signal processing, vol. 49, no. 11, pp. 2713-2720, 2001.

[10] Z. U. Sheikh and H. Johansson, "A class of wide-band linear-phase FIR differentiators using a two-rate approach and the frequencyresponse masking technique," IEEE Transactions on Circuits and Systems I: Regular Papers, vol. 58, no. 8, pp. 1827-1839, 2011.

[11] P. N. Lekic and A. D. Micic, "Direct synthesis of the digital FIR fullband differentiators," Facta universitatis-series: Electronics and Energetics, vol. 15, no. 3, pp. 465-479, 2002.

[12] J.-J. Shyu, S.-C. Pei, and Y.-D. Huang, "Least-squares design of variable maximally linear fir differentiators," IEEE transactions on signal processing, vol. 57, no. 11, pp. 4568-4573, 2009.

[13] P. N. Lekic, A. D. Micic, J. D. Ristic, and J. B. Lekic, "Design of second order digital FIR full-band differentiators using weighting coefficients," IETE Journal of Research, vol. 56, no. 1, pp. 22-29, 2010.

[14] V. D. Pavlovic and P. N. Lekic, "Design of The First Order Digital FIR Differentiators," Facta universitatis-series: Electronics and Energetics, vol. 8, no. 2, pp. 235-253, 1995

[15] V. D. Pavlovic and P. N. Lekic, "Design of the First and Higher Order Digital FIR Full-Band Differentiators," in The International Conference on Signal Processing Applications and Technology : 1997 ICSPAT Conference Proceedings, San Diego, 1997, pp. 663-667.

[16] R. C. Nongpiur, D. J. Shpak, and A. Antoniou, "Design of IIR digital differentiators using constrained optimization," IEEE Transactions on Signal Processing, vol. 62, no. 7, pp. 1729-1739, 2014.

[17] M. A. Al-Alaoui, "Novel digital integrator and differentiator," Electronics letters, vol. 29, no. 4, pp. 376-378, 1993.

[18] M. A. Al-Alaoui, "Novel approach to designing digital differentiators," Electronics Letters, vol. 28, no. 15, pp. 1376-1378, 1992.

[19] M. A. Al-Alaoui, "Novel IIR differentiator from the Simpson integration rule," IEEE Transactions on Circuits and Systems I: Fundamental Theory and Applications, vol. 41, no. 2, pp. 186-187, 1994.

[20] M. A. Al-Alaoui, "A class of second-order integrators and low-pass differentiators," IEEE Transactions on Circuits and Systems I Fundamental Theory and Applications, vol. 42, no. 4, pp. 220-223, 1995.

[21] M. A. Al-Alaoui, "Class of digital integrators and differentiators," IET Signal processing, vol. 5, no. 2, pp. 251-260, 2011.

[22] O. P. Goswami, T. K. Rawat, and D. K. Upadhyay, "A novel approach for the design of optimum IIR differentiators using fractional interpolation," Circuits, Systems, and Signal Processing, vol. 39, no. 3, pp. 1688-1698, 2020.

[23] T. A. A. Ali, Z. Xiao, J. Sun, S. Mirjalili, V. Havyarimana, and H. Jiang, "Optimal design of IIR wideband digital differentiators and integrators using salp swarm algorithm," Knowledge-Based Systems, vol. 182, p. 104834, 2019.

[24] X. Zhang, "Design of maximally flat IIR filters with flat group delay responses," Signal Processing, vol. 88, pp. 1792-1800, 2008.

[25] L. Rabiner and K. Steiglitz, "The design of wide-band recursive and nonrecursive digital differentiators," IEEE Transactions on Audio and Electroacoustics, vol. 18, no. 2, pp. 204-209, 1970.

[26] M. Fogiel et al., Handbook of mathematical, scientific, and engineering formulas, tables, functions, graphs, transforms. Research \& Education Assoc., 1984. 